\title{
We somehow imagined it, now we know! What an opportunity!
}

\author{
Stefanos Demertzis, MD
}

\footnotetext{
From the Department of Cardiac Surgery, Cardiocentro Ticino, Lugano, Ticino, Switzerland, Faculty of Medicine, University of Bern, Bern, Switzerland, and Faculty of Biomedical Sciences, University of Italian Switzerland, Lugano, Ticino, Switzerland.

Disclosures: Author has nothing to disclose with regard to commercial support.

Received for publication July 1, 2018; accepted for publication July 2, 2018; available ahead of print Aug 21, 2018.

Address for reprints: Stefanos Demertzis, MD, Department of Cardiac Surgery, Cardiocentro Ticino, Via Tesserete 48, CH-6900 Lugano, Switzerland (E-mail: demertzis@ cardiocentro.org).

J Thorac Cardiovasc Surg 2018;156:2123

$0022-5223 / \$ 36.00$

Copyright (c) 2018 by The American Association for Thoracic Surgery

https://doi.org/10.1016/j.jtcvs.2018.07.010
}

Despite recommendations in recent guidelines, ${ }^{1,2}$ there is no well-defined indication of when to prophylactically resect the aorta in patients with aortopathy associated with bicuspid aortic valves (BAVs). Nobody knows exactly how to approach it: More or less aggressively when compared with the usual degenerative dilatations and aneurysms, or similar or different to genetically triggered aortic disease such as Marfan syndrome? What is the main cause of the aortopathy-genetics or flow-mediated biomechanics? The rich body of literature provided by Bollache and colleagues ${ }^{3}$ show how many approaches, theories, and therapeutic strategies were developed trying to shed light on this complex issue.

The value of the article is in the association of quantitative histopathology (thickness of elastic fibers) of aortic specimens to regional wall shear stress (WSS) measured by means of 4-dimensional-flow magnetic resonance imaging and biaxial tissue stiffness on patients with BAVassociated aortopathy, either with prevalent stenosis or prevalent regurgitation. All values were compared with healthy control patients. Several conclusions could significantly influence how we treat our patients in the future.

First, there is a correlation between quantitative in vivo regional aortic WSS and elastic fiber thickness and biomechanical properties of the aortic wall tissue in BAV. Increased in vivo regional aortic WSS is significantly associated with elastic fiber thinning and with impaired tissue biomechanics, particularly in moderately dilated aortas (diameter $<45 \mathrm{~mm}$ ) and in aortic valve stenosis.

Next, BAV-mediated aortic tissue changes are influenced by the predominant hemodynamic alteration of the BAV, stenosis (correlation to WSS and thickness of elastic fibers), or regurgitation (correlation not significant).

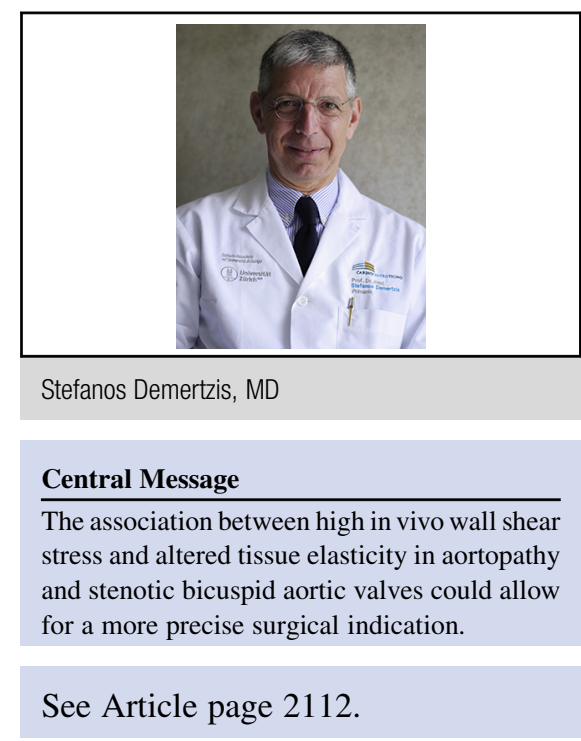

The results presented by Bollache and colleagues ${ }^{3}$ suggest that stenotic and regurgitant BAV-associated aortopathies are distinct entities with different mechanisms in their pathogenesis. The only missing dimension of this study is the genetic aspect, both in terms of family history and genetic analysis. Based on these findings, larger studies, including 4-dimensional-flow magnetic resonance imaging with WSS measurements, could lead to a more precise and perhaps personalized indications for prophylactic aortic resection in patients with BAV. Our scientific community is invited to seize the opportunity and transform these initial results into scientifically sound clinical knowledge by conducting carefully designed multicenter studies sufficiently powered to address these issues.

\section{References}

1. Nishimura RA, Otto CM, Bonow RO, Carabello BA, Erwin JP, Guyton RA, et al 2014 AHA/ACC guideline for the management of patients with valvular heart disease: a report of the American College of Cardiology/American Heart Association task force on practice guidelines. J Thorac Cardiovasc Surg. 2014;148:e1-132.

2. Falk V, Baumgartner H, Bax JJ, De Bonis M, Hamm C, Holm PJ, et al. 2017 ESC/ EACTS guidelines for the management of valvular heart disease. Eur J Cardiothorac Surg. 2017;52:616-64.

3. Bollache E, Guzzardi DG, Sattari S, Olsen KE, Di Martino ES, Malaisrie SC, et al Aortic valve-mediated wall shear stress is heterogeneous and predicts regional aortic elastic fiber thinning in bicuspid aortic valve-associated aortopathy. $J$ Thorac Cardiovasc Surg. 2018;156:2112-20.e2. 